\title{
Editorial
}

\section{Functional Nanomaterials for Renewable Energy and Sustainability}

\author{
Xiulin Fan, ${ }^{1}$ Xuezhang Xiao, ${ }^{2}$ and Zheng Zhang $^{3}$ \\ ${ }^{1}$ Department of Chemical \& Biomolecular Engineering, University of Maryland, College Park, MD 20742, USA \\ ${ }^{2}$ School of Materials Science and Engineering, Zhejiang University, Hangzhou 310027, China \\ ${ }^{3}$ Center for Functional Nanomaterials, Brookhaven National Laboratory, Upton, NY 11973, USA
}

Correspondence should be addressed to Xiulin Fan; xlfan@umd.edu

Received 6 February 2017; Accepted 6 February 2017; Published 19 March 2017

Copyright (C) 2017 Xiulin Fan et al. This is an open access article distributed under the Creative Commons Attribution License, which permits unrestricted use, distribution, and reproduction in any medium, provided the original work is properly cited.

Modern societies thrive on an unprecedented level of energy consumption, which places a tremendous amount of stress on our environment. Indeed, energy renewability and environmental sustainability stand to be some of the most pressing challenges of our time. Continuous efforts have been devoted to the development of renewable alternative energies, particularly via environmentally friendly green synthesis methods, in order to address these two critically important and interconnected issues. This special issue to be published in 2017 aims at reporting recent progresses in renewable energies and green synthesis method. We have selected seven papers, representing three different technical frontiers of this topic: three on photovoltaics for solar energy conversion, two on sensor materials, and two on rechargeable lithium-ion batteries.

Solar Energy Conversion. V. Gâté et al. demonstrated a solar cell module, which leverages nanostructuring and a sol-gel process to improve the cost effectiveness of solar energy conversion.

W. M. N. M. B. Wanninayake et al. synthesized $\mathrm{SnO}_{2}$ semiconductor nanoparticles and constructed a dye-sensitized solar cell prototype, achieving a conversion efficiency of $5.04 \%$.

S. R. Lee et al. designed five types of conjugated phenylene polymer-modified photoanodes for quantum dot-sensitized solar cells.
Sensor Materials. R. Galos et al. fabricated a nanosensor module with electrospun piezoelectric (PZT) nanofibers, capable of more accurate measurement on nanoscale.

H. Xuemei et al. achieved a dramatic enhancement of the sensing characteristics of cubic $\operatorname{In}_{2} \mathrm{O}_{3}$, by fabricating $p-n$ heterojunction-like $\mathrm{NiO} / \mathrm{In}_{2} \mathrm{O}_{3}$ composite microparticles as sensor material.

Rechargeable Lithium-Ion Batteries. M. V. Tran et al. synthesized a spinel $\mathrm{Li}_{4} \mathrm{Ti}_{5} \mathrm{O}_{12}$ with size of $\sim 100 \mathrm{~nm}$, using $\mathrm{LiOH}$ and $\mathrm{Ti}(\mathrm{OBu})_{4}$ as precursor, and found excellent discharge capacity and rate capabilities.

M. Liang et al. proposed an arc plasma evaporationoxidation method to synthesize $\mathrm{Fe}_{2} \mathrm{O}_{3}$-based nanocomposites. As the anode material, this nanocomposite showed a high capacity of more than $500 \mathrm{mAh} / \mathrm{g}$ over 150 cycles.

\section{Acknowledgments}

We would like to extend our thanks to all authors who responded to our call for papers.

Xiulin Fan Xuezhang Xiao Zheng Zhang 

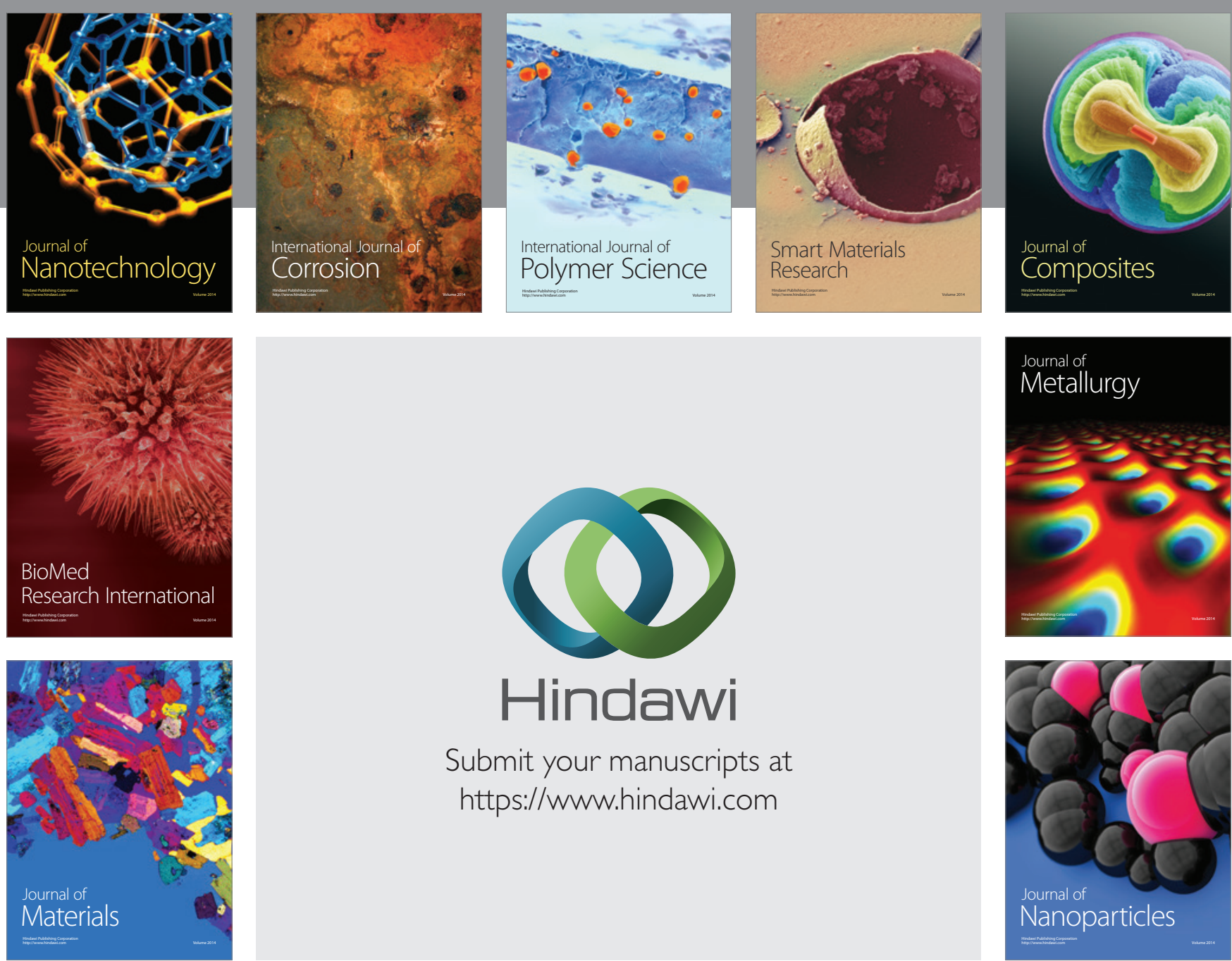

\section{Hindawi}

Submit your manuscripts at

https://www.hindawi.com

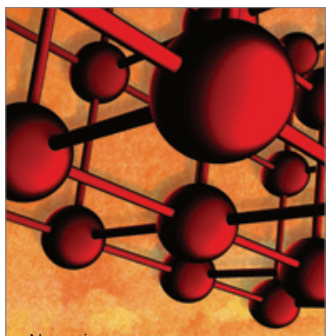

Materials Science and Engineering
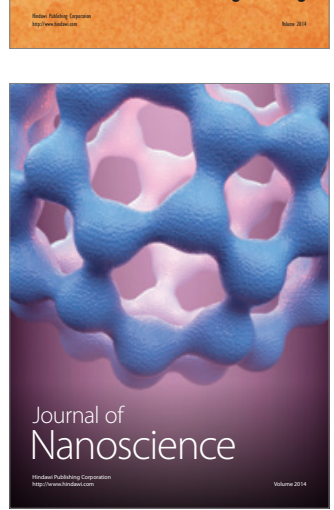
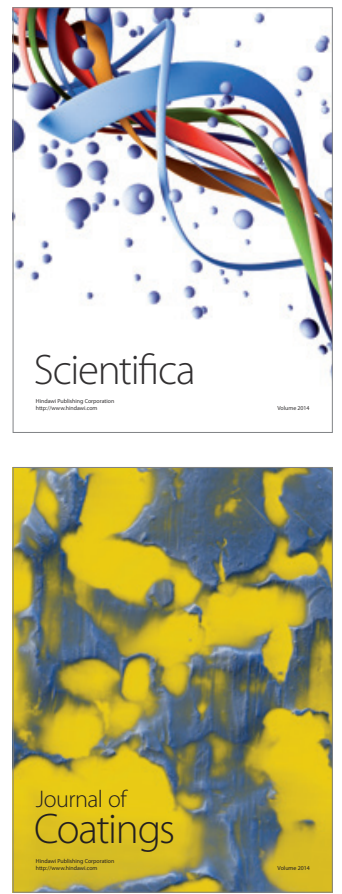
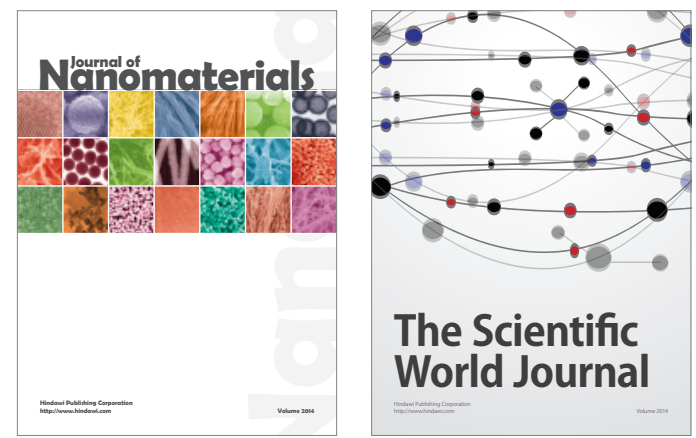

The Scientific World Journal
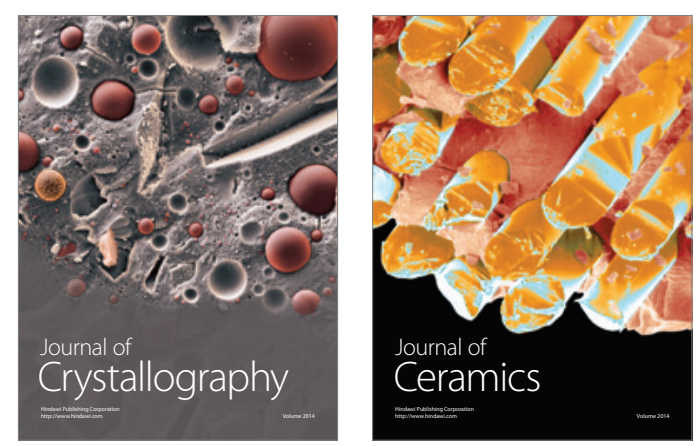
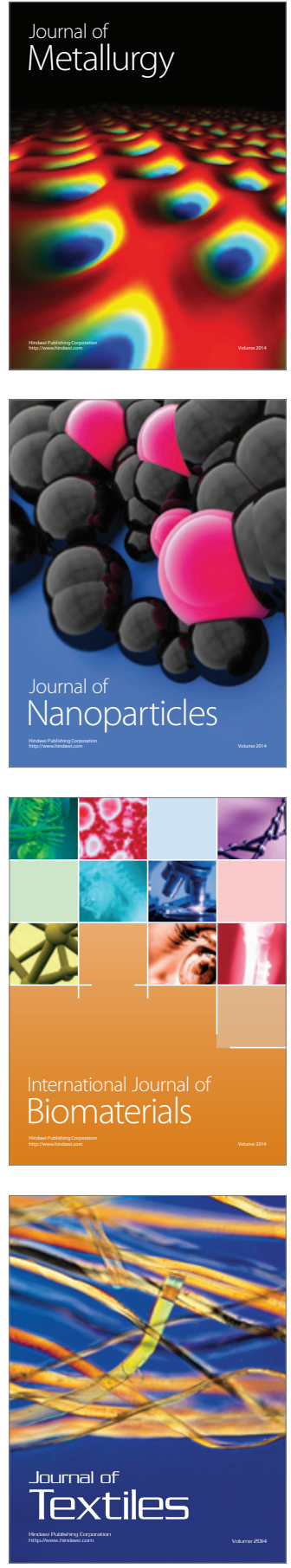